\title{
Abstract-Where There's Smoke, There's Fire: Analyzing the Explicit and Implicit Effects of Text-Based and Graphic Warning Labels on Cigarette Packages
}

\author{
Nadine Hennigs, Steffen Schmidt, Sascha Langner, \\ Evmorfia Karampournioti, and Levke Albertsen
}

\begin{abstract}
In order to increase the awareness of the negative effects of smoking, warning messages were applied to cigarette packages all around the globe. As such warning messages receive high level and frequency of exposure at the point of sale, they are supposed to be highly effective in influencing both health beliefs (attitudes) and smoking-related behavior. However, previous studies on the effectiveness of warning messages rely on respondents' self-reported reactions. Reasoning the potential bias of social desirability as well as the respondents' ability, motivation, and willingness to answer such questions in a reliable manner "these answers may not reflect actual behavior and hence may not provide an objective assessment of the effect of graphic warnings" (Azagba and Sharaf 2013, p. 709). The present study takes a different approach by assessing the explicit and implicit (automatic) effects of different warning messages on cigarette packages. The objective is to answer two main research questions: Do smokers react differently regarding self- and otheroriented warning messages and pictures on cigarette packages? Which combination of messages and pictures offers the biggest impact on attitude regarding smoking on an implicit and explicit level? Our results show that the impact on the attitude regarding the product (cigarette package) greatly differs regarding the used combination of picture and message content on the conscious and unconscious level.
\end{abstract}

\footnotetext{
N. Hennigs $(\square) \bullet S$. Schmidt $\bullet$ S. Langner • E. Karampournioti $\bullet$ L. Albertsen

Leibniz University of Hannover, Hannover, Germany

e-mail: hennigs@m2.uni-hannover.de; schmidt@m2.uni-hannover.de;

langner@m2.uni-hannover.de; karampournioti@m2.uni-hannover.de;

albertsen@m2.uni-hannover.de
} 